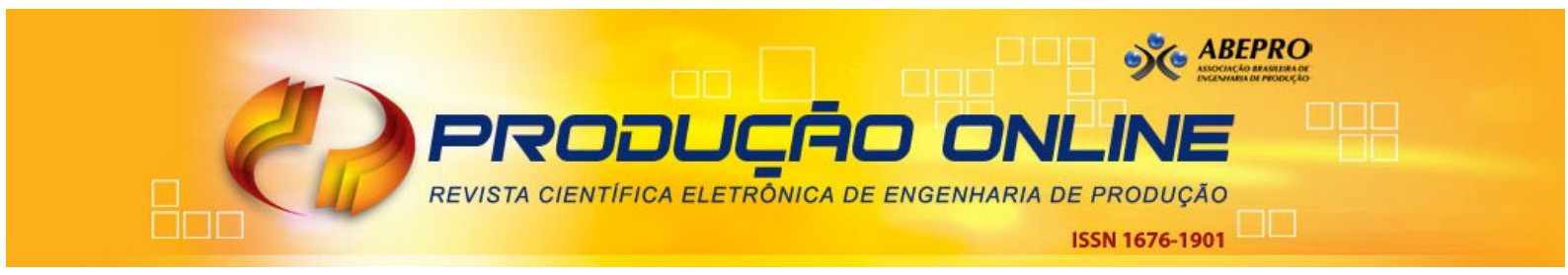

\title{
AVALIAÇÃO DA EFICIÊNCIA ENERGÉTICA NA ILUMINAÇÃO PÚBLICA: PROPOSTA DE MODELAGEM CONSIDERANDO A VARIABILIDADE CLIMÁTICA
}

\section{EVALUATION OF ENERGY EFFICIENCY IN STREET LIGHTING: MODEL PROPOSITION CONSIDERING CLIMATE VARIABILITY}

\author{
Amaury Caruzzo* E-mail: acaruzzo@gmail.com \\ Luiz Augusto Horta Nogueira** E-mail: horta@unifei.edu.br \\ *Instituto Tecnológico de Aeronáutica (ITA), São José dos Campos, SP \\ **Universidade Federal de Itajubá (UNIFEI), Itajubá, MG
}

Resumo: O objetivo deste artigo é propor uma metodologia para avaliar os impactos da variabilidade climática no consumo eficiente de energia elétrica na iluminação pública no Brasil. Foi aplicado o Método por Demanda Climática (MDC) e calculado a economia de energia das ações do Programa Nacional de lluminação Pública Eficiente (ReLuz) em 2005, considerando a climatologia mensal de insolação, desagregadas por mesorregiões brasileiras. Pelo MDC, a economia total de energia na iluminação pública em 2005 foi estimado em $63 \mathrm{GWh} /$ ano ou 1,39\% superior do valor determinado pelo ReLuz/Eletrobrás e uma redução na demanda de ponta de aproximadamente $15 \mathrm{MW}$, considerando os quase 393 mil pontos atendidos no ReLuz neste ano. Os resultados indicam que, além da diferença de latitude, a variabilidade climática nas diferentes mesorregiões é um fator que amplia em até $19 \%$ o tempo de utilização diário das lâmpadas na iluminação pública. Além disso, devido às dimensões do Brasil, os padrões de sazonalidade na economia de energia não são homogêneos e tem uma correlação entre a variabilidade mensal de insolação e a latitude das mesorregiões avaliadas. O uso do MDC também demostrou ser adequado para determinar um ranking das mesorregiões com os maiores índices de economia de energia por ponto de iluminação pública.

Palavras-chaves: Engenharia de Energia. Método por Demanda Climática. Climatologia. Insolação. Procel.

\begin{abstract}
This paper assesses the impacts of climate variability on efficient electricity consumption in street lighting in Brazil. The Climate Demand Method (CDM) was applied, and the energy savings achieved by Brazil's National Efficient Street Lighting Program (ReLuz) in 2005 were calculated, considering the monthly climatology of sunshine duration, disaggregated by county in Brazil. The total energy savings in street lighting in 2005 were estimated at $63 \mathrm{GWh} /$ year or $1.39 \%$ higher than the value determined by ReLuz/Eletrobrás and there was a $15 \mathrm{MW}$ reduction in demand in Brazil, considering the nearly 393,000 points in ReLuz served in 2005. The results indicate that, besides the difference in latitude, climate variability in different county increases the daily usage of street lighting up to $19 \%$. Furthermore, Brazil's large size means that seasonality patterns in energy savings are not homogeneous, and there is a correlation between the monthly variability in sunshine duration and the latitude of mesoregions. The CDM was also shown to be suitable for ranking mesoregions with the highest levels of energy saving lighting.
\end{abstract}

Keywords: Energy engineering. Climatic demand method. Climate. sunshine duration. Procel. 


\section{INTRODUÇÃO}

O aumento da demanda de energia e a crescente preocupação com os impactos das mudanças climáticas têm intensificado o desenvolvimento de pesquisas e o uso de tecnologias mais eficientes no consumo de energia (SOLA et al., 2006; CARDOSO; NOGUEIRA; HADDAD, 2010; BAKER; SOLAK, 2011; DUBOIS; BLOMSTERBERG, 2011; LI; YANG; LAM, 2012). Outro aspecto não menos importante, é a elevação dos custos na geração de energia elétrica. Neste sentido, diversas ações de eficiência energética estão sendo realizadas, como os programas de incentivo para a mudança nos hábitos de consumo da população ou para o uso de equipamentos que consomem energia de forma mais racional (BLADH, 2011; CARDOSO et al., 2011; NOGUEIRA et al., 2015).

O Programa Nacional de Conservação de Energia Elétrica (PROCEL) é desenvolvido pela Eletrobrás e tem o objetivo de ampliar o uso mais eficiente da energia em suas diversas formas. O PROCEL promove a redução nos custos de investimento do setor energético brasileiro e dos respectivos impactos ambientais indesejáveis resultantes da produção de energia (ELETROBRÁS, 2006; NOGUEIRA et al., 2015). Na iluminação pública (IP), o PROCEL através de um subprograma chamado ReLuz (Programa Nacional de Iluminação Pública Eficiente), também estimula o uso de tecnologias mais eficientes (LOPES, 2002; FRÓES-DA-SILVA, 2006). Até o ano de 2005, o ReLuz estimou que a economia de energia acumulada na IP devido à expansão e substituição por lâmpadas mais eficientes foi da ordem em 973 GWh/ano (ELETROBRÁS, 2006, p.147).

O grande desafio do PROCEL/ReLuz, está em estabelecer uma metodologia para quantificar de forma precisa os ganhos das ações de conservação de energia (KOOMEY et al., 2010; HEO; ZAVALA, 2012). Isto é, determinar qual é a real economia de energia promovida pela substituição por lâmpadas mais eficientes. Vale destacar que na IP, a duração do dia e as condições climáticas, em espacial a insolação têm uma relação direta no consumo de energia, já que as lâmpadas são acionadas quando existe baixa claridade natural (FRÓES-DA-SILVA, 2006; KOSTIC; DJOKIC, 2009). 
Neste contexto, o objetivo deste trabalho é propor uma metodologia para avaliar os impactos da variabilidade climática mensal por mesorregiões brasileiras no consumo de energia na iluminação pública por lâmpadas mais eficientes. Para isso, foi utilizado uma base de dados que integre as condições climáticas no Brasil (insolação), com informações técnicas do ReLuz (parque de lâmpadas) e geográficas (divisão por mesorregiões).

\section{FUNDAMENTAÇÃO TEÓRICA}

Nesta seção são apresentadas considerações teóricas relevantes para o desenvolvimento da proposta de metodologia, descrita na Seção 3.

\subsection{Clima e insolação}

Das variáveis meteorológicas, a insolação é o principal fator relacionando ao consumo de energia elétrica na iluminação pública. Como definição, a insolação (solar) é o número de horas de duração do brilho do Sol ou da incidência da luz direta do Sol na superfície terrestre (INMET, 1999; WMO, 2008). A insolação tem uma forte dependência da latitude local, da nebulosidade e do dia do ano, devido às variações posição do Sol na esfera celeste (AHRENS, 1994; FERRARO; IGAWA; MARINELLI, 2010), como pode ser observado na Figura 1.

Figura 1 - Variação anual da posição do Sol observada em latitude média (45ㅇ)

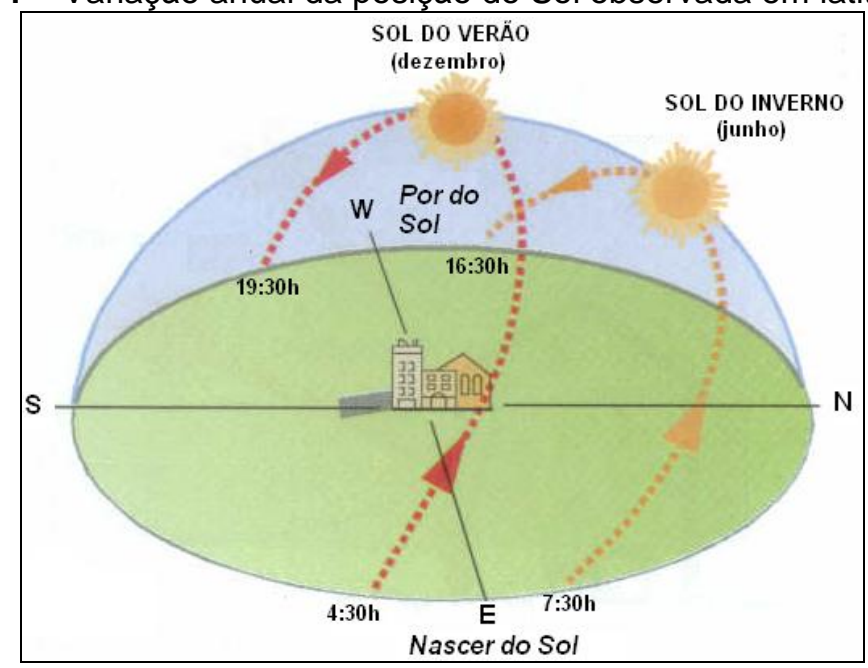

Fonte: adaptado de Ahrens (1994)

Revista Produção Online, Florianópolis, SC, v.15, n. 4, p. 1399-1425, out./dez. 2015. 
O instrumento meteorológico para observar a insolação é o heliógrafo (Figura 2) (WMO, 2008). O heliógrafo é um instrumento de fácil operação, custos iniciais e operacionais reduzidos e com disponibilidade de dados climatológicos para vários pontos no Brasil. Portanto este equipamento é a melhor alternativa para obter valores que indicam as variações de luminosidade de uma determinada localização. O Brasil possui algumas centenas de estações meteorológicas com séries de dados de no mínimo 30 anos de observação. Apesar da imprecisão dos dados do heliógrafo (mensurável pela queima da tira, Figura 2-b), vale destacar que nenhum outro instrumento de observação solar possui um conjunto de dados climatológicos amplos e diversificado (vários pontos). Assim, foram utilizados neste trabalho os dados de insolação de estações meteorológicas de superfície convencionais, como informação climatológica oficial proveniente do Instituto Nacional de Meteorologia (INMET) (INMET, 2009).

Figura 2 - Heliógrafo Stokes-Campbell (a) e os diferentes modelos da tira de cartolina (b), utilizado para medir o tempo de insolação diária

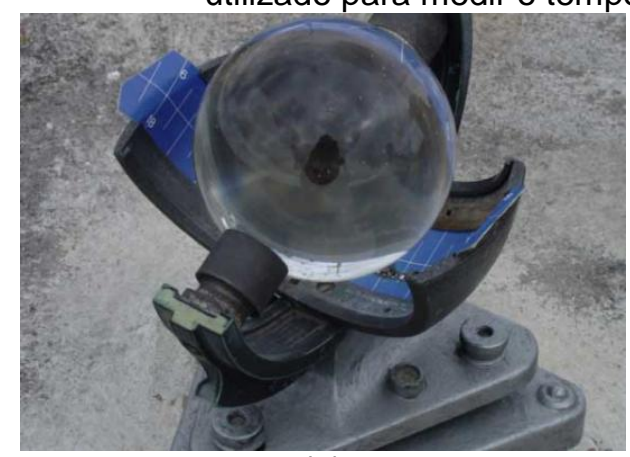

(a)

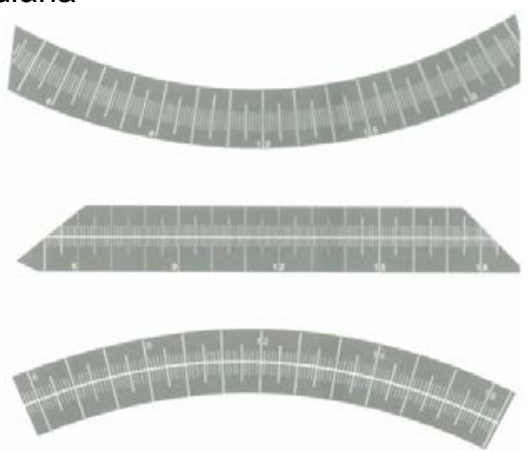

(b)

Fonte: Elaboração dos autores

\subsection{Variabilidade climática e consumo energia}

$\mathrm{Na}$ literatura existem diversos estudos que relacionam as condições climáticas com o consumo de energia. Entretanto, a maior parte destas pesquisas é concentrada nos impactos da demanda de energia no planejamento de projetos arquitetônicos ou na carga térmica de refrigeradores e condicionadores de ar. Em outras palavras, identificam os fatores principais nas mudanças na temperatura e na 
variação térmica devido à posição do Sol (GELLER et al., 2004; BOUYER; INARD; MUSY, 2011; PASA et al., 2012; KWAK et al., 2013).

Poucos artigos internacionais apresentam resultados que considerem os impactos da nebulosidade e da insolação no consumo de energia devido à demanda de iluminação (GHISI; GOSCH; LAMBERTS, 2007; BHANDARI; SHRESTHA; NEW, 2012). Diferente do Brasil, nos países desenvolvidos a demanda por energia térmica, para o resfriamento ou calefação, é muito superior a da iluminação. Ao avaliar a demanda de energia brasileira, Oliveira; Silveira; Braga (2000) destacam que ao considerar somente o impacto da temperatura, não é possível explicar os padrões de sazonalidade nas diferentes regiões brasileiras. Com base nos resultados, os autores sugerem que outros aspectos além da temperatura devem ser considerados, como por exemplo, os impactos das outras variáveis climáticas e os hábitos de consumo nas regiões de grande concentração populacional.

Para a IP no Brasil, a Associação Brasileira de Normas Técnicas (ABNT) estabelece parâmetros de funcionamento por meio das normas NBR-5101 (lluminação pública - Procedimento) e NBR-5123 (Relé fotelétrico e tomada para iluminação). Nestas normas são definidos entre outros critérios, os valores de iluminância (claridade) mínima e máxima recomendada para a operação dos sistemas de IP. Isto é, o funcionamento da IP é automática e estabelecida por níveis pré-determinados de iluminância local, com o acionamento no início e desligamento, no final do período noturno (LOPES, 2002; WOJNICKI et al., 2014). Outros impactos também podem ser considerados na IP, como o bem estar da população, o melhor uso de espaços de lazer, a importância para redução de acidentes automobilísticos, a influência na questão da criminalidade ou ainda para a arquitetura das cidades (FRÓES-DA-SILVA, 2006; KOSTIC; DJOKIC, 2009).

\section{METODOLOGIA}

A metodologia utilizada neste trabalho é denominada como Método por Demanda Climática para IP (MDC-IP). Este método foi desenvolvido a partir do número de pontos expandidos e substituídos na IP pelo ReLuz. Foi avaliado o tempo de utilização na IP considerando as condições climáticas mensais, com uma 
desagregação regional através das 137 mesorregiões brasileiras (definição do Instituto Brasileiro de Geografia e Estatística - IBGE). A seguir, serão apresentadas as cinco etapas sequenciais de desenvolvimento do modelo proposto para o cálculo de economia de energia na IP.

\subsection{Número de pontos na IP (etapa 1)}

Nos relatórios anuais de avaliação do Programa ReLuz, a Eletrobrás disponibiliza a relação dos Estados e municípios atendidos. Com base no relatório de 2005 (ELETROBRÁS, 2006), foi possível determinar o número de pontos substituídos e expandidos no ReLuz nas cidades atendidas e separadas por mesorregião brasileira. Segundo Eletrobrás (2006), para o ano de 2005, foram 3.324 pontos de expansão (novos) e 389.613 de substituição, com o total de 392.937 novas lâmpadas eficientes na IP, distribuídas em 43 mesorregiões no Brasil.

\subsection{Insolação e fator climático (etapa 2)}

Foi utilizada a base de dados de insolação a partir das Normais Climatológicas do Brasil - 1961-1990 provenientes do Instituto Nacional de Meteorologia (INMET, 2009) e do Atlas Solarimétrico do Brasil (TIBA, 2003). Ambos oferecem os valores climatológicos com observações em mais de 200 estações meteorológicas espalhadas pelo País. Todas as estações meteorológicas utilizadas são classificadas como Estações Sinóticas de Superfície (convencionais), fazem parte da rede mundial de observação da Organização Meteorológica Mundial e são identificadas através uma numeração internacional. Portanto, é uma longa base de dados oficiais, que podem ser comparadas com outras estações no mundo e sem a necessidade de instalar novos equipamentos. A partir da listagem com as cidades atendidas no ReLuz em 2005, foi identificado a estação meteorológica correspondente ou a mais representativa (próxima) para cada mesorregião.

Como a insolação é um parâmetro de observação direta do Sol, é dependente da latitude e das condições atmosféricas locais, como nebulosidade, presença de nevoeiros, poluição, entre outros fatores (WMO, 2008; FERRARO; IGAWA; 
MARINELLI, 2010; LI et al., 2011). Para uma mesma latitude ocorrem variações nos valores médios de insolação (Figura 3). Por ser informações climatológicas, estes valores de insolação representam um dia médio de uma série de 30 anos. Portanto rápidas perturbações diárias, como a passagem de nebulosidade sobre o heliógrafo no meio do dia e sem relação com o funcionamento dos sistemas de IP, não são significativas.

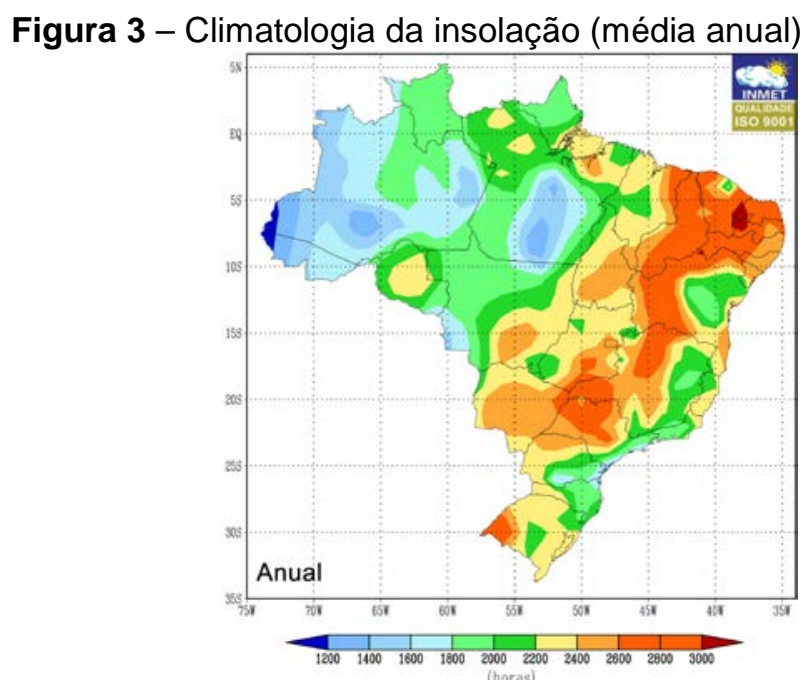

Fonte: (INMET, 2009)

\subsection{Tempo de utilização na IP (etapa 3)}

Devido aos altos custos, a medição do tempo de utilização (TU) na IP não é realizada pelas concessionarias de energia elétrica de forma permanente. Por praticidade a Agência Nacional de Energia Elétrica (Aneel) estabeleceu na Resolução Normativa no 414/2010 (BRASIL, 2010) o tempo a ser considerado para consumo diário na IP, de 11 (onze) horas e 52 (cinquenta e dois) minutos de funcionamento, com um total de aproximadamente 4.333 horas no ano.

Através de um projeto realizado pela Concessionária de Energia Elétrica Light Serviços de Eletricidade S.A., foram medidos entre abril de 2005 e agosto de 2006 os TU diários na IP para a cidade do Rio de Janeiro (QUADROS, 2006a; 2006b). Foram feitas observações em seis pontos diferentes da cidade, sendo coletados dados diários e consolidados mensalmente, com valores de TU médio na IP para cada mês do ano (Tabela 1).

Revista Produção Online, Florianópolis, SC, v.15, n. 4, p. 1399-1425, out./dez. 2015. 
Tabela 1 - Tempo de utilização observado nos seis diferentes pontos na cidade do Rio de Janeiro no projeto da Light e cálculo do fator $\beta$ para IP, mensal e médio anual

\begin{tabular}{ccccccccccccc}
\hline Estação & Jan & Fev & Mar & Abr & Mai & Jun & Jul & Ago & Set & Out & Nov & Dez \\
\hline P-1 & $10: 07$ & $10: 34$ & $11: 07$ & $11: 44$ & $11: 22$ & $12: 46$ & $12: 44$ & $12: 41$ & $12: 00$ & $11: 25$ & $10: 51$ & $10: 11$ \\
P-2 & $10: 45$ & $12: 17$ & $11: 33$ & $13: 07$ & n.d. & $16: 32$ & $13: 48$ & $13: 58$ & $13: 36$ & $12: 48$ & $11: 45$ & $12: 07$ \\
P-3 & $10: 26$ & $11: 25$ & $11: 26$ & $12: 25$ & $12: 50$ & $13: 57$ & $13: 00$ & $13: 13$ & $12: 28$ & $12: 09$ & $11: 14$ & $11: 03$ \\
P-4 & $10: 37$ & $10: 52$ & $11: 25$ & $12: 04$ & $12: 53$ & $12: 59$ & $13: 03$ & $12: 45$ & $12: 23$ & $11: 46$ & $11: 19$ & $10: 34$ \\
P-5 & $10: 43$ & $11: 36$ & $11: 42$ & $12: 12$ & $12: 33$ & $13: 28$ & $12: 57$ & $12: 58$ & $12: 23$ & $12: 03$ & $11: 08$ & $11: 01$ \\
P-6 & $10: 31$ & $10: 55$ & $11: 35$ & $12: 05$ & n.d. & $13: 34$ & $13: 48$ & $12: 55$ & $12: 38$ & $11: 36$ & $11: 13$ & $10: 32$ \\
$\begin{array}{c}\text { Média } \\
\text { horária }\end{array}$ & $\mathbf{1 0 : 3 1}$ & $\mathbf{1 1 : 1 6}$ & $\mathbf{1 1 : 2 8}$ & $\mathbf{1 2 : 1 6}$ & $\mathbf{1 2 : 2 4}$ & $\mathbf{1 3 : 5 2}$ & $\mathbf{1 3 : 1 3}$ & $\mathbf{1 3 : 0 5}$ & $\mathbf{1 2 : 3 4}$ & $\mathbf{1 1 : 5 7}$ & $\mathbf{1 1 : 1 5}$ & $\mathbf{1 0 : 5 4}$ \\
$\begin{array}{c}\text { Média } \\
\text { (décimos) }\end{array}$ & 10,52 & 11,27 & 11,47 & 12,27 & 12,40 & 13,87 & 13,22 & 13,08 & 12,57 & 11,95 & 11,25 & 10,90 \\
$\begin{array}{c}\text { Beta } \\
\text { (mensal) }\end{array}$ & $\mathbf{0 , 0 2 2}$ & $\mathbf{0 , 0 2 7}$ & $\mathbf{0 , 0 4 9}$ & $\mathbf{0 , 0 2 5}$ & $\mathbf{0 , 1 1 3}$ & $\mathbf{0 , 1 3 3}$ & $\mathbf{0 , 0 2 5}$ & $\mathbf{0 , 0 8 7}$ & $\mathbf{0 , 0 8 3}$ & $\mathbf{0 , 0 8 3}$ & $\mathbf{0 , 0 6 4}$ & $\mathbf{0 , 0 5 2}$ \\
$\begin{array}{c}\text { Beta médio anual } \\
(\boldsymbol{\beta})=\mathbf{0 , 0 2 9}\end{array}$ & & & & & & & & &
\end{tabular}

n.d. = não disponível

Fonte: Elaboração dos autores, a partir de Quadros, 2006a e 2006b

Na Figura 4, é apresentada uma comparação com três indicadores de TU diferentes sendo, a legislação da Aneel, dados teóricos (considerando somente a noite teórica, devido à latitude) e TU médio observado para todos os seis pontos de medição do projeto. Para os dois últimos, é possível observar a sazonalidade bem característica entre o verão e inverno.

Importante destacar que o TU das lâmpadas na IP tem uma alta variabilidade no Brasil devido às diferenças de latitude e clima. Portanto, para estimar a economia de energia pelo MDC-IP, foi classificado o TU das lâmpadas na IP em duas categorias:

i) $\mathrm{TU}$ padrão $=\mathrm{TU}_{\text {pad }}$ (valor fixo adotado pela legislação ou pelo PROCEL)

ii) TU variável $=$ TUvar (valor variável devido as diferenças de latitude e clima) 
Figura 4 - Tempo de utilização na IP médio observado na cidade do Rio de Janeiro, teórico e pela resolução da Aneel

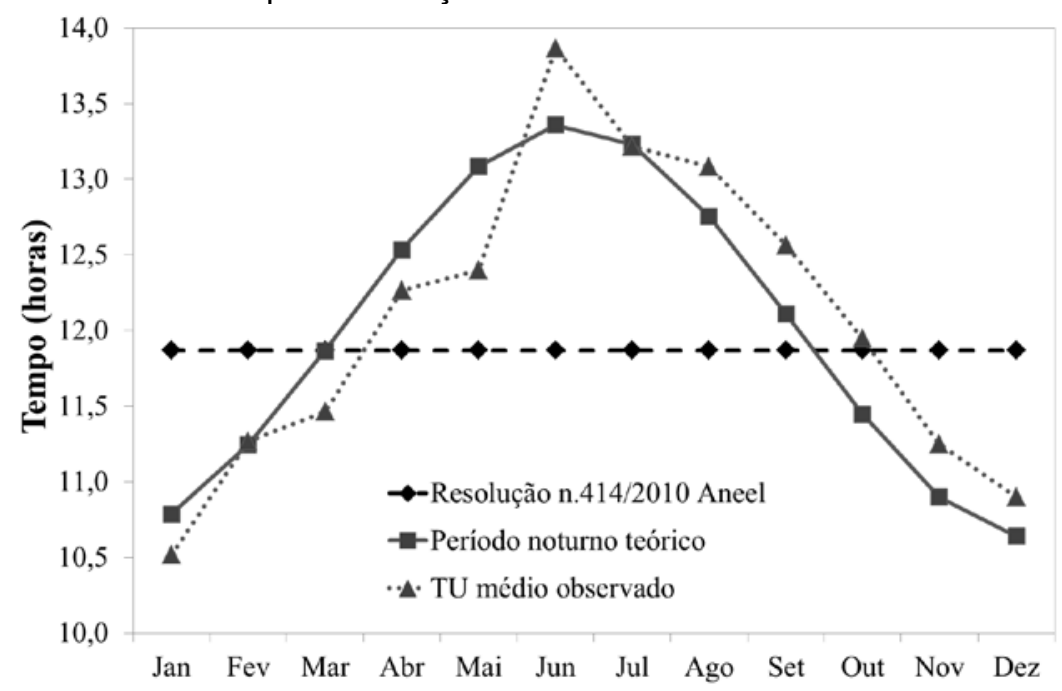

Fonte: Elaboração dos autores a partir de (VIANELLO; ALVES, 1991; QUADROS, 2006a; BRASIL, 2010)

A desagregação do TU como será apresentado a seguir, é uma forma de considerar a variabilidade nas mesorregiões avaliadas. Assumindo que todas as lâmpadas na IP são susceptíveis aos efeitos de latitude e clima, a partir da modelagem proposta foi desenvolvida uma equação geral, para todas as mesorregiões e meses do ano, sendo:

$$
T U_{i j}=T U_{p a d}+\left(12-T d_{i j}\right)+\left(T d_{i j}-I_{i j}\right) \beta
$$

em que:

$T U_{i j}=$ tempo de utilização da IP da mesorregião "i" e mês "j" (horas)

$T U_{\text {pad }}=$ tempo de utilização padrão na IP adotado pela legislação vigente para consumo diário (11 horas e 52 minutos)

12 = duração do dia claro teórico na latitude $0^{\circ}$

$T d_{i j}=$ duração média do dia claro teórico, na mesorregião "i" e no mês "ji”, dado pelas equações 2 e 3 (horas)

$l_{i j}=$ insolação média mensal na mesorregião "i" e mês do ano "j" (horas)

$\beta$ = fator de correção do TU (variação climática)

A duração do dia claro teórico ( $T d$ ) é considerado como o período em que o Sol permanece acima do plano do horizonte em um ponto sobre a superfície da Terra de latitude ' $\phi$ ' e dia do ano ' $n$ ' (denominado também de Fotoperíodo). O Td Revista Produção Online, Florianópolis, SC, v.15, n. 4, p. 1399-1425, out./dez. 2015. 
pode ser calculado pelas equações abaixo (VIANELLO; ALVES, 1991; VAREJÃOSILVA, 2005).

$$
\begin{aligned}
& \delta=23,45 \sin \left(\frac{360(284+n)}{365}\right) \\
& T d=\frac{2}{15} \arccos (-\tan \phi \tan \delta)
\end{aligned}
$$

em que:

$\delta$ = declinação solar ao longo do ano (graus)

23,45 = valor em décimos de grau da inclinação do eixo de rotação da Terra em relação ao Plano da Eclíptica (ou $23^{\circ} 27^{\prime}$ )

$T d=$ duração do dia claro teórico (horas)

$n=$ dia Juliano do ano

$\phi=$ latitude da localização (graus)

De acordo a Equação 1, o TU pad representa tempo de utilização padrão na IP adotado pela legislação vigente, com valor diário de 11 horas e 52 minutos/dia (BRASIL, 2010). O TU variável (TUvar) é uma função das modificações ambientais, indicados pelos termos: $(12-T d)$, para latitude e $(T d-I)$, para o clima. Desse modo pode ser estimado o valor de TU médio mensal na IP considerando a variabilidade de latitude e clima para cada uma das 137 mesorregiões brasileiras. 0 fator de correção do TU $(\beta)$ é utilizado para a calibração do MDC-IP por mesorregião. O termo $\beta$ é um ajuste relacionado aos sistemas automático de acionamento da IP (relé fotoeletrônico) e da sazonalidade da diferença entre o dia claro teórico e a insolação da mesorregião considerada.

A partir do projeto realizado pela Light Serviços de Eletricidade (QUADROS, 2006b), foi possível determinar o ajuste na relação do TU na IP, isto é, o fator de correção $(\beta)$. Isolando este termo na Equação 1, foi estimado o valor do $\beta$ para a IP (Tabela 1) e aplicado posteriormente nas cálculos. Por ser um valor empírico o ajuste $\beta$ é inicialmente válido somente para a cidade do Rio de Janeiro, pois em outras mesorregiões as características do TU são diferentes. Logo, o termo $\beta$ é um valor definido a priori através das observações do projeto da concessionária Light.

Revista Produção Online, Florianópolis, SC, v.15, n. 4, p. 1399-1425, out./dez. 2015. 
Por outro lado, na ausência de outras medições do TU na IP no Brasil, foi adotado neste trabalho o valor único calculado do $\beta$ médio anual (Tabela 1 ) para estimar o TU mensal de cada mesorregião (Equação 1). Contudo espera-se que com a maior disponibilidade de observações de TU, que este parâmetro possa ser aperfeiçoado no futuro, já que o termo $\beta$ tem variabilidade temporal (mensal) e espacial (mesorregião).

\subsection{Demais parâmetros do MDC-IP (passo 4)}

$\mathrm{Na}$ aplicação do MDC-IP foi necessário realizar uma série de premissas devido à ausência de alguns dados. A falta de informações disponíveis e de fácil acesso, como o número total de pontos de IP em operação no País (separadas por município) e a respectiva potência destas lâmpadas (individualmente) são as grandes dificuldades para estimar as curvas de consumo. Assim foi utilizado uma Redução Média de Potência (RMP) na substituição e expansão do ReLuz em 2005 e um valor fixo de Fator de Coincidência de Ponta (FCP), pois o período de operação dos sistemas de IP coincide com a ponta da curva de carga do sistema elétrico nacional (19h - 21h), como indicado no Quadro 1.

Quadro 1 - Outros parâmetros utilizados no MDC-IP

\begin{tabular}{lcc}
\multicolumn{1}{c}{ Variável } & Unidades & MDC-IP \\
\hline Fator de Coincidência de Ponta (FCP) & $\%$ & 100 (ou 1,0) \\
\hline $\begin{array}{l}\text { Redução média de potência (RMP) (estimado a partir de: } \\
\text { Eletrobrás, 2006) }\end{array}$ & $\mathrm{W}$ & 40 (aproximado) \\
\hline
\end{tabular}

\subsection{Cálculo da economia de energia (passo 5)}

No MDC-IP, a economia de energia foi estimada pela Equação 4, sendo esta uma somatória das economias de energia mensais de cada mesorregião:

$$
E E_{\text {total }}=\sum_{i=1}^{137} \sum_{j=12}^{12} E E_{i j}=N_{i} R M P T U_{i j}
$$

em que:

$E E_{\text {total }}=$ economia de energia total real estimada

Revista Produção Online, Florianópolis, SC, v.15, n. 4, p. 1399-1425, out./dez. 2015. 
$E E_{i j}=$ economia de energia real estimada na mesorregião "i", no mês "j"

$N_{i}=$ número de lâmpadas substituídas e de expansão na mesorregião "i"

$R M P=$ redução média de potência estimada para todas as lâmpadas de IP no ano

$T U_{i j}=$ tempo de utilização da lâmpada em IP na mesorregião "i", no mês "j"

A redução de demanda de ponta em IP foi determinada pela Equação 5:

$$
R D P_{\text {total }}=\sum_{i=1}^{137} R D P_{i}=N_{i} R M P F C P
$$

em que:

$R D P_{\text {total }}=$ redução de demanda de ponta total

$R D P_{i}=$ redução de demanda de ponto na mesorregião " $i$ "

$N_{i}=$ número de lâmpadas substituídas e de expansão na mesorregião "i"

$R M P=$ redução média de potência estimada para todas as lâmpadas de IP no ano

$F C P=$ fator de coincidência de ponta para IP

\section{RESULTADOS}

Os resultados gerais estimados pelo Método por Demanda Climática para a iluminação pública estão apresentados na Tabela 2.

Tabela 2 - Resultados gerais do MDC-IP.

\begin{tabular}{lc}
\multicolumn{1}{c}{ Resultados do MDC } & Valor estimado para IP \\
\hline Economia de energia total & $63.036 \mathrm{MWh} / \mathrm{ano}$ \\
TU mínimo diário & 9,9 horas \\
TU mínimo ano (365 dias) & 4.367 horas \\
TU máximo diário & 14,2 horas \\
TU máximo ano (365 dias) & 4.415 horas \\
Redução Demanda de Ponta (RDP) & $15.510 \mathrm{~kW}$ \\
\hline
\end{tabular}

\subsection{Mesorregiões com valores extremos de insolação}

Com a finalidade de avaliar os padrões sazonais, foram selecionados casos próximos dos extremos dos valores de insolação e suas respectivas correlações com a economia de energia. A partir da lista de cidade atendidas pelo ReLuz em 2005 foram identificadas três mesorregiões distintas. Entretanto estas mesorregiões não correspondem necessariamente aos valores mínimos ou máximos do Brasil. Das

Revista Produção Online, Florianópolis, SC, v.15, n. 4, p. 1399-1425, out./dez. 2015. 
mesorregiões atendidas pelo ReLuz, a 'Centro Oriental Paranaense' (Paraná) obteve o valor próximo do mínimo e 'Oeste Potiguar' (Rio Grande do Norte) obteve o valor máximo. Para efeito de comparação, foi utilizada a mesorregião 'Metropolitana de Belo Horizonte' que possui um valor intermediário de insolação total anual (Quadro 2).

Quadro 2 - Características das mesorregiões correspondentes a valores máximo, mínimo e intermediário de insolação

\begin{tabular}{c|c|c|c}
\hline Mesorregião & $\begin{array}{c}\text { Centro Oriental } \\
\text { Paranaense }\end{array}$ & $\begin{array}{c}\text { Metropolitana de } \\
\text { Belo Horizonte }\end{array}$ & Oeste Potiguar \\
\hline Características da insolação (I) & Mínima & Intermediária & Máxima \\
\hline Insolação total anual (horas) & 1.909 & 2.569 & 3.041 \\
\hline Num. Municípios atendidos (2005) & 1 & 4 & 6 \\
\hline $\begin{array}{c}\text { Num. lâmpadas ReLuz } \\
\text { (subs + exp.) }\end{array}$ & 2.013 & 389 & Apodi \\
\hline $\begin{array}{c}\text { Estação meteorológica } \\
\text { representativa }\end{array}$ & Castro & Belo Horizonte & $-5,39$ \\
\hline $\begin{array}{c}\text { Latitude (graus) } \\
\text { Período (normal climatológica) } \\
(19 X X)\end{array}$ & $-24,47$ & $-19,56$ & $61 / 90$ \\
\hline
\end{tabular}

Nas Figuras 5-a e 5-b são apresentados os valores médios diários de insolação e a estimativa do TU das três mesorregiões selecionadas. É possível identificar a correlação entre a insolação e o TU.

Figura 5 - Valores médio diários de insolação (a) e tempo de utilização estimado (b) para lâmpadas nas três mesorregiões, correspondente a máximos, mínimos e intermediário anual

Insolação diária

10

média em horas)

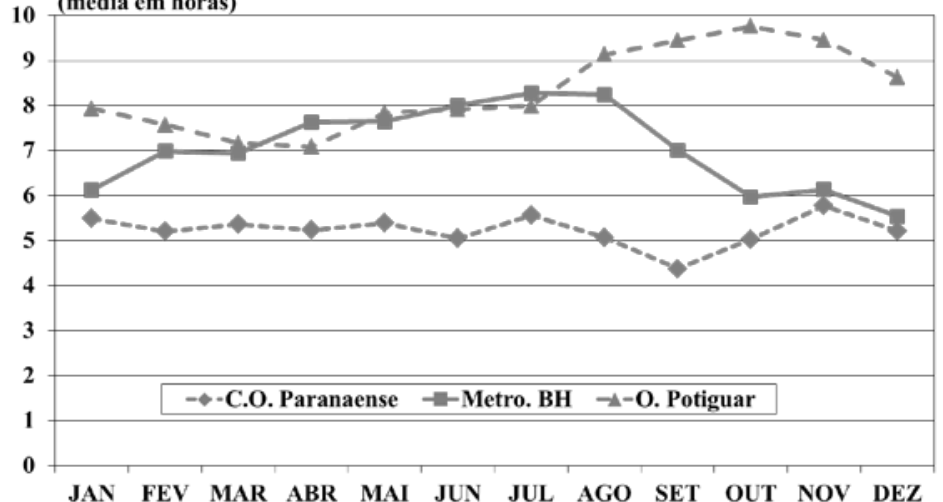

(a)

Revista Produção Online, Florianópolis, SC, v.15, n. 4, p. 1399-1425, out./dez. 2015. 


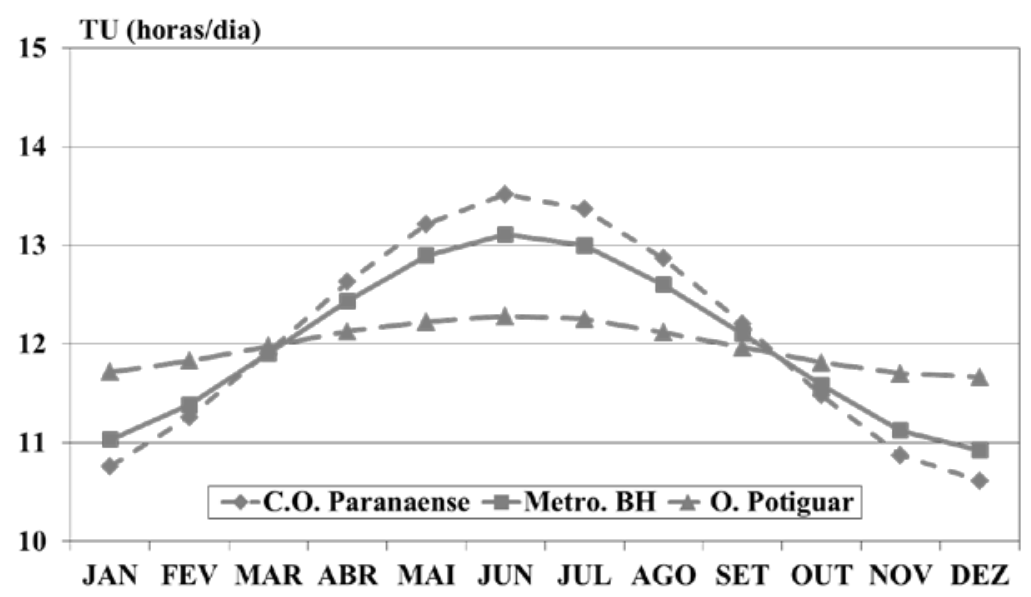

(b)

Para latitudes mais baixas, como é o caso da mesorregião 'Oeste Potiguar', quase não existe sazonalidade na diferença entre o dia claro teórico e a insolação (Figura 6-a) e na economia de energia (Figuras 6-b). Já para as demais mesorregiões com latitudes mais altas, é possível identificar uma sazonalidade bem definida, com os máximos de economia durante o inverno.

Figura 6 - Média da diferença entre o dia claro e a insolação (a) e Economia de Energia Específico estimada (b) nas três mesorregiões selecionadas

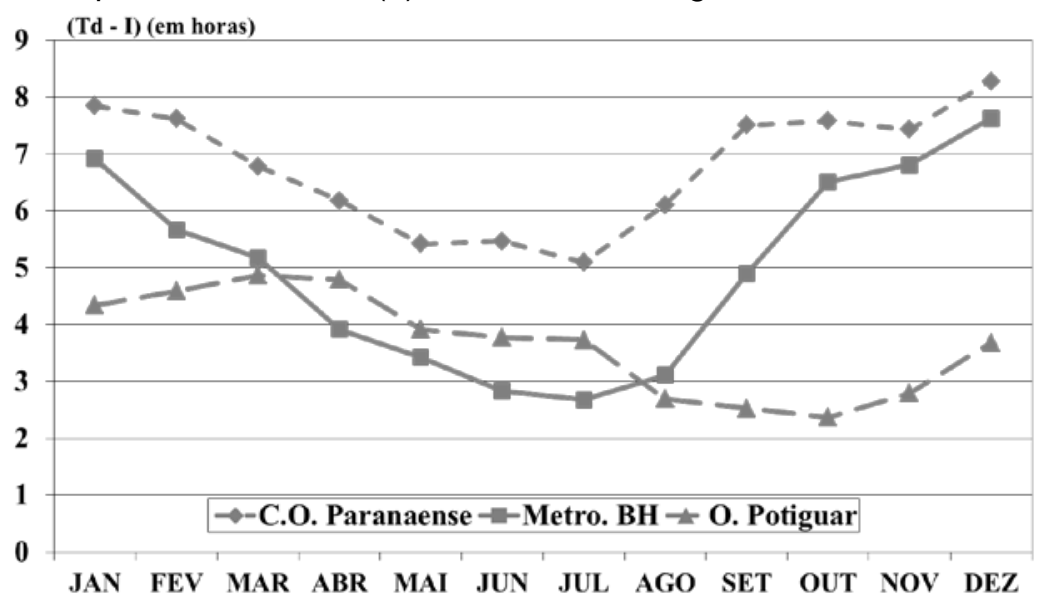

(a) 


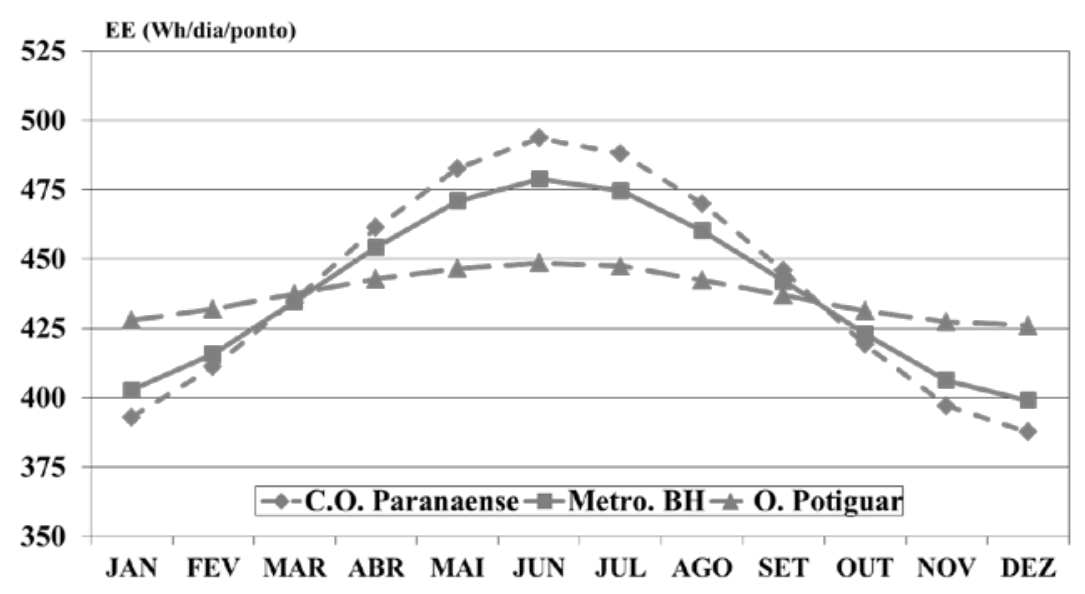

(b)

\subsection{Mesorregiões com padrão de insolação anual invertido}

Também foram identificadas nas mesorregiões atendidas pelo ReLuz em 2005, duas com observações de insolação com um padrão anual invertido, além de uma terceira sem uma sazonalidade significante para comparação. No Quadro 3 são apresentados os principais valores para as três mesorregiões selecionadas, sendo a 'Sudoeste Rio-Grandense' (padrão $U$ ), 'Leste Rondoniense' ( $U$ invertido) e de 'Ribeirão Preto' (intermediário).

Quadro 3 - Características das mesorregiões com valores padrão $U, U$ invertido e intermediário de insolação.

\begin{tabular}{c|c|c|c}
\hline Mesorregião & $\begin{array}{c}\text { Sudoeste Rio- } \\
\text { grandense }\end{array}$ & Ribeirão Preto & $\begin{array}{c}\text { Leste } \\
\text { Rondoniense }\end{array}$ \\
\hline Características da insolação (I) & Padrão U & Intermediário & Padrão $\cap$ \\
\hline Insolação total anual (horas) & 2.182 & 2.496 & 1 \\
\hline $\begin{array}{c}\text { Num. Municípios atendidos } \\
\text { (2005) }\end{array}$ & 1 & 19 & 60 \\
\hline $\begin{array}{c}\text { Num. lâmpadas ReLuz } \\
\text { (subs + exp.) }\end{array}$ & 4.522 & 25.069 & Diamantino/MT \\
\hline $\begin{array}{c}\text { Estação meteorológica } \\
\text { representativa }\end{array}$ & Bagé & Franca & $-14,24$ \\
\hline Latitude (graus) & $-31,20$ & $-20,33$ & $62 / 90$ \\
\hline $\begin{array}{c}\text { Período (normal climatológica) } \\
\text { (19XX) }\end{array}$ & $61 / 90$ & $61 / 90$ & \\
\hline
\end{tabular}

A mesorregião 'Sudoeste Rio-Grandense' apresenta os máximos de insolação no verão (curva em $U$ ). Por outro lado, o 'Leste Rondoniense' segue o padrão com os máximos de insolação durante o inverno (curva $U$ invertido) e de forma mais suave, a mesorregião 'Ribeirão Preto' possui uma sazonalidade reduzida entre verão 
e inverno (Figura 7-a). Na Figura 7-b são apresentados os valores estimados de TU, sendo que quanto maior a latitude, mais significante é a amplitude entre verão e inverno.

Figura 7 - Valores médio diários de insolação (a) e tempo de utilização estimado (b) das três mesorregiões, com padrão U, U invertido e intermediário

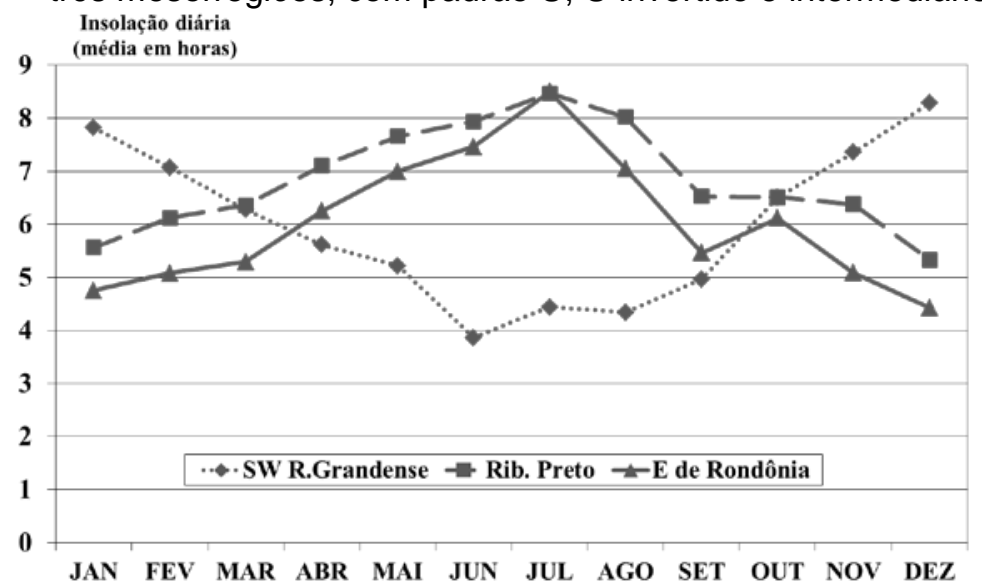

(a)

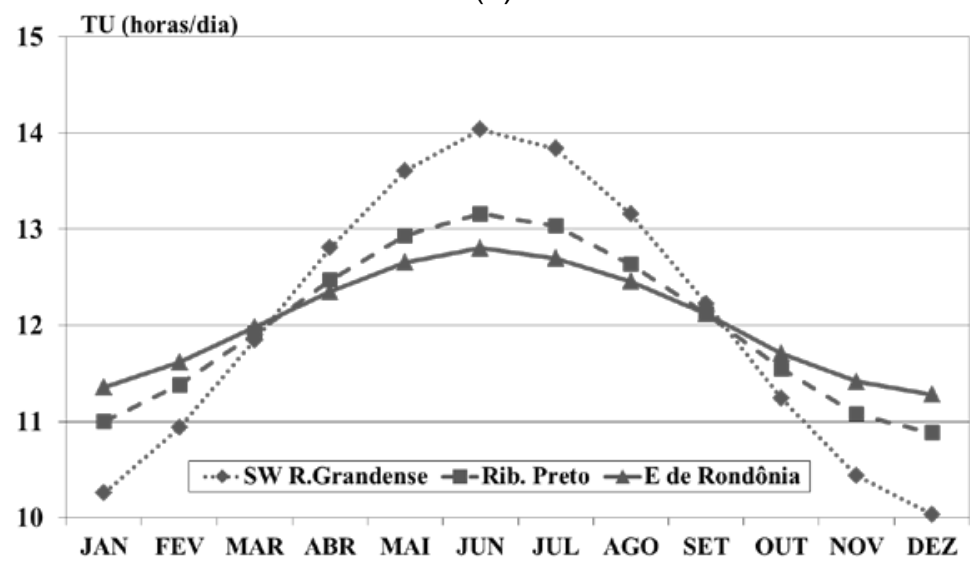

(b)

Nas Figuras 8-a e 8-b é possível observar que a maior economia ocorre durante o inverno no Brasil, onde o uso de IP é intensificado pelas noites mais longas.

Revista Produção Online, Florianópolis, SC, v.15, n. 4, p. 1399-1425, out./dez. 2015. 
Figura 8 - Média da diferença entre o dia claro e a insolação (a) e Economia de Energia Específica (b) estimada nas três mesorregiões selecionadas

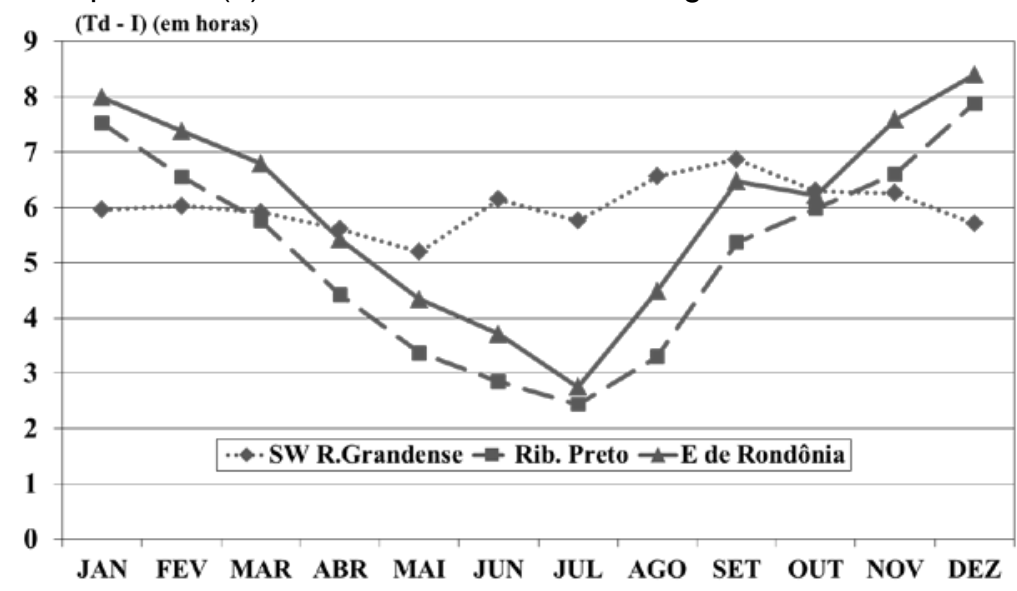

(a)

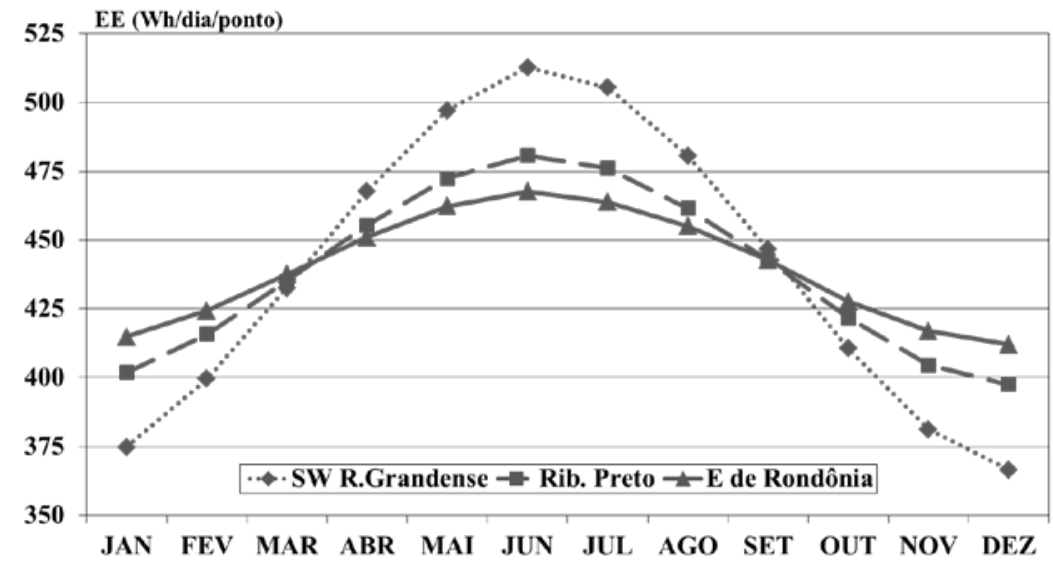

(b)

\subsection{Ranking das mesorregiões}

Através da Economia de Energia Específica por ponto de IP, foi possível estimar um ranking com as mesorregiões de proporcionaram maiores economia de energia calculada pelo MDC-IP (Quadro 4). Entretanto este valores são válidos apenas para as cidades atendidas pelo ReLuz em 2005.

Quadro 4 - Ranking parcial das mesorregiões com as maiores economia de energia estimado para o ReLuz em 2005 por ponto de IP.

\begin{tabular}{cc|ccc}
\hline Ranking & Mesorregião Geográfica & UF & $\begin{array}{c}\text { Economia de Energia (média anual } \\
\text { - Wh/dia/ponto de IP) }\end{array}$ \\
\hline 1 & Norte Catarinense & SC & 441,5 \\
\hline 2 & Litoral Sul Paulista & SP & 441,2 \\
\hline 3 & Centro Fluminense & RJ & 441,1 \\
\hline 4 & Serrana & SC & 441,1 \\
\hline 5 & Vale do Itajaí & SC & 440,8 \\
\hline
\end{tabular}

Revista Produção Online, Florianópolis, SC, v.15, n. 4, p. 1399-1425, out./dez. 2015. 
É possível identificar que para a IP, o ranking de economia energia tem uma relação com dois fatores: i) as mesorregiões que possuem as maiores latitudes; ii) menores valores de insolação, que neste caso são na sua maioria nos estados das regiões Sul e Sudeste do Brasil.

\section{DISCUSSÃO}

O funcionamento da IP ocorre durante todo o período noturno até o início do dia claro, portanto a variação de latitude é muito mais significativa na sazonalidade do que a variabilidade climática. Neste contexto a IP opera de forma automática, independente de uma demanda dos usuários nas vias públicas. Apesar dos pontos de IP funcionarem basicamente em função da duração da noite, a redução da insolação proporciona uma ampliação no TU devido à presença de nebulosidade. Como identificado em outros trabalhos (IHM; NEMRI; KRARTI, 2009; DE ROSA et al., 2010), as diferentes condições climáticas podem, ao longo do ano, ampliar ou reduzir a sazonalidade no consumo de energia. Consequentemente, o clima também amplia a economia de energia nos pontos atendidos pelo ReLuz, pois ocorre um aumento na demanda de iluminação. Esta característica pode ser identificada na redução do dia claro, que correspondente ao termo $(T d-I)$ da Equação 1 , sendo a diferença entre o dia claro teórico e a insolação (Figuras 6-a e 8-a).

Em comparação ao relatório de avaliação anual da Eletrobrás podemos destacar que o MDC-IP apresentou valores totais de economia de energia um pouco superiores (+866 MWh/ano) aos obtidos pelo PROCEL (Tabela 3), pois insere a variabilidade climática mensal na demanda de energia na IP. Além disso, foi possível obter um refinamento através do ajuste mensal e regional com a estimativa de economia de energia por mesorregiões.

Tabela 3 - Comparação dos resultados de economia de energia e RDP obtidos para 2005

\begin{tabular}{ccc}
\hline Referência & $\begin{array}{c}\text { Economia de energia } \\
\text { (MWh/ano) }\end{array}$ & RDP (kW) \\
\hline MDC-IP & 63.036 & 15.510 \\
Eletrobrás, 2006 & 62.170 & 15.510 \\
\hline
\end{tabular}

Revista Produção Online, Florianópolis, SC, v.15, n. 4, p. 1399-1425, out./dez. 2015. 
Na IP o principal fator de operação é o TU, pois não existem outros fatores externos que podem influenciar a demanda de energia, como o hábito de consumo nas diferentes regiões do País ou o consumo por faixa de renda (KOSTIC; DJOKIC, 2009). Na resolução da Aneel, assim como para as estimativas do PROCEL, são utilizados valores fixo de TU com o tempo padrão entre $11 \mathrm{~h} 52 \mathrm{~m}$ e 12h/dia, respectivamente.

Como contribuição, vale ressaltar que, através do MDC-IP foi possível identificar que existe uma imprecisão no uso de um valor fixo de TU, pois os efeitos da latitude associados com as condições climáticas regionais provocam uma significativa variação no uso da IP ao longo do ano (Figuras 4, 5-b e 7-b). A variação do TU nas mesorregiões atendidas pelo ReLuz tem o valor mínimo diário estimado de 9,9 horas/dia e um total anual de 4.367 horas/ano. Já para valores máximos diários, o TU estimado ficou 14,2 horas/dia, com um total anual de 4.415 horas/ano. Portanto, somente esta variação entre os valores mínimo e máximo em função da latitude e das condições climáticas, justificaria o aperfeiçoamento da abordagem para determinar o TU que considere as características regionais do Brasil.

Por outro lado, a variabilidade climática provoca efeitos distintos no padrão de sazonalidade. O clima brasileiro apresenta em grande parte do País uma estação chuvosa durante o verão (dezembro a março) e uma estação seca durante o inverno (junho a agosto). A estação seca esta relacionada com a redução de nebulosidade que provoca um aumento da insolação na superfície e diminui a demanda de energia por iluminação durante o inverno. Entretanto este comportamento não é homogêneo em todo o Brasil. Através da Figura 9 é possível identificar a variabilidade nos valores climatológicos mensais de precipitação e insolação em diversas localidades do País.

No Estado do Rio Grande do Sul (Figura 9), o balanço entre o dia claro mais curto (noites mais longas) no inverno e redução da insolação, proporciona um efeito compensatório. Esta característica também pode ser identificada na Figura 8-a, onde a diferença entre o dia claro e a insolação $(T d-I)$ tem um valor aproximadamente constante ao longo do ano para a mesorregião 'Sudoeste Rio-Grandense'. Por outro lado, este comportamento não é observado nas mesorregiões de 'Ribeirão Preto' e 'Leste Rondoniense' (também na Figura 8-a). Deste modo, em função da correlação com a latitude, a variabilidade da insolação pode ampliar ou reduzir a sazonalidade do TU (diferença entre as curvas das Figuras 5-b e 7-b). 
Figura 9 - Mapa do Brasil com gráficos anuais de precipitação (coluna) e de insolação (linha) em algumas regiões do Brasil

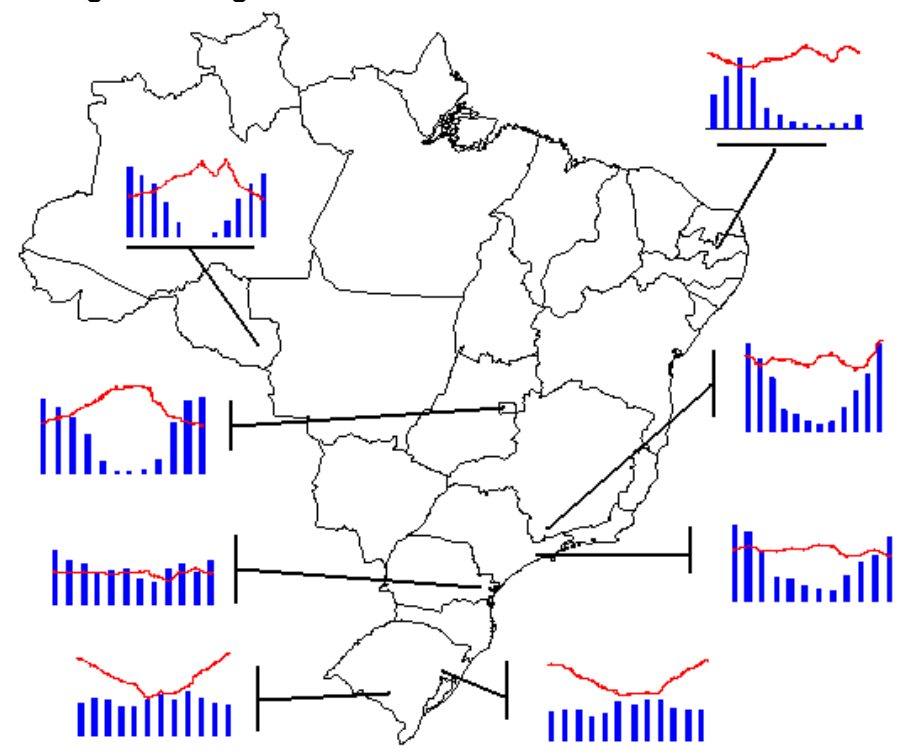

Fonte: Elaboração dos autores, a partir de (INMET, 2009)

No Quadro 5 são discutidas as correlações entre o dia claro teórico $(T d)$ e a insolação $(I)$ de algumas das mesorregiões analisadas. Através do Coeficiente de correlação de Pearson, foram indicadas o grau de correlação com valores entre -1 a 1. Estas características correspondem diretamente à influência das condições climáticas na demanda por iluminação. No Apêndice são apresentados os gráficos e os respectivos valores das correlações das mesorregiões analisadas.

Quadro 5 - Correlações entre a diferença do dia claro teórico e insolação de algumas mesorregiões analisadas

\begin{tabular}{|c|c|c|}
\hline Correlação (Td vs I) & Efeitos do clima no TU e EE & Justificativa \\
\hline \multicolumn{3}{|c|}{ Leste Rondoniense e Distrito Federal } \\
\hline (-) correlação forte negativa & $\begin{array}{c}\text { aumenta a amplitude do TU e do } \\
\text { consumo de energia }\end{array}$ & $\begin{array}{c}\text { estação seca ocorre no inverno e } \\
\text { chuvoso no verão }\end{array}$ \\
\hline \multicolumn{3}{|c|}{ Sudoeste Rio-Grandense e Metropolitana de Porto Alegre } \\
\hline (+) correlação forte positiva & $\begin{array}{c}\text { diminui a amplitude do TU e do } \\
\text { consumo de energia }\end{array}$ & inverno com chuva mais intensa \\
\hline \multicolumn{3}{|c|}{ Oeste Potiguar e Centro Oeste Paranaense } \\
\hline sem correlação (fraca) & $\begin{array}{c}\text { sem correlação definida (I não modifica } \\
\text { sazonalidade de TU e EE) }\end{array}$ & $\begin{array}{l}\text { a insolação não tem grandes } \\
\text { variações ao longo do ano }\end{array}$ \\
\hline
\end{tabular}

Como descrição geral da climatologia, podemos afirmar que todas as regiões do Brasil apresentam de alguma maneira, uma estação chuvosa e uma estação seca ao longo do ano. Como apresentado em INPE (1996) e Cavalcanti et al. (2009), a maior parte do Sudeste e do Centro-Oeste, sob a influência de sistemas subtropicais, a estação chuvosa concentra-se nos meses de verão e a estiagem, nos meses do inverno com uma 
sazonalidade bem definida. Na região Norte, o clima equatorial chuvoso garante precipitação praticamente o ano todo. No Nordeste do Brasil, apesar de manter o padrão de estação chuvosa e seca, o período de ocorrência tem uma variabilidade espacial e temporal, pois a região é largamente influenciada pelas condições atmosféricas e oceânicas em escala regional e global. Já os estados do Sul do Brasil, são marcados por uma distribuição quase uniforme de chuva ao longo do ano, com uma elevação durante o inverno, visto que sofrem a influência dos sistemas de latitudes médias, especialmente os sistemas frontais que se deslocam do Sul. Vale destacar também que a chuva e a insolação são grandezas com uma forte correlação, independente do tipo de nebulosidade envolvida no processo precipitante (LI et al., 2011; MARTÍNEZ-CHICO; BATLLES; BOSCH, 2011; TERAMOTO; ESCOBEDO, 2012).

É conveniente mencionar como limitação deste trabalho de aplicação do MDC-IP que não foi considerado na estimativa de economia de energia os seguintes efeitos: a) horário de verão (ARIES; NEWSHAM, 2008), adotado em alguns estados do Brasil; b) degradação das lâmpadas durante o tempo de operação que provoca uma redução no desempenho (CARDOSO; NOGUEIRA; HADDAD, 2010; CARDOSO et al., 2011).

\section{CONSIDERAÇÕES FINAIS}

O objetivo deste artigo foi propor uma metodologia para avaliar o impacto da variabilidade climática mensal por mesorregião brasileira na economia de energia das lâmpadas eficientes na IP. Os valores totais (anual) calculados pelo Método por Demanda Climática na iluminação pública ficaram próximos aos estimados pela Eletrobrás, mas a inovação da proposta em estimar a economia de energia mensal e a redução na demanda de ponta desagregada por mesorregião demostrou ser adequada. Para o ano base 2005 o MDC-IP estimou uma economia superior ao PROCEL em 1,39\% (Tabela 3), devido refinamento do método proposto que considera os diversos climas na operação dos pontos de IP. Vale destacar que todos estes valores foram baseados nos quase 393 mil pontos de substituição e expansão neste ano.

Na iluminação pública o TU é função predominante da duração da noite. Entretanto, a redução da insolação amplia a demanda de energia devido ao escurecimento do ambiente. Nesta situação, as condições climáticas sempre aumentam a demanda por iluminação, onde caso sejam utilizadas lâmpadas com tecnologias mais eficientes, também 
haverá uma ampliação na economia de energia. Esta demanda pode ser através do acionamento antecipado ou do desligamento posterior dos pontos de IP em um determinado dia.

Pelo MDC-IP a variabilidade de latitude e da insolação pode modificar o TU diário em até $19 \%$ em relação aos valores diários (fixo) da resolução da Aneel e do PROCEL. Portanto, como uma das contribuições, este trabalho demonstra a necessidade de uma revisão das normas na IP, que por considerar valores fixos sem avaliar as condições climáticas regionais, estima uma diferença de TU anual na IP de quase $2 \%$. Importante ressaltar que em pouquíssimos casos também pode ocorrer o acionamento do ponto de IP durante o dia, devido ao escurecimento do céu decorrente de uma tempestade severa, com altos índices de precipitação. Entretanto, como foi utilizado dados climatológicos de insolação, este tipo de efeito (perturbações diárias) é minimizado.

Com a aplicação do MDC-IP também foi possível identificar a sazonalidade no consumo e os distintos efeitos da variabilidade climáticas na respectiva economia de energia das mesorregiões atendidas pelo ReLuz (Quadro 5). A caracterização da sazonalidade da demanda na IP é extremamente relevante para o planejamento na geração, transmissão e distribuição da energia elétrica no País. Este parâmetro, entre outros fatores são importantes para os picos de consumo e tem o objetivo de manter o equilíbrio entre a oferta e a demanda de eletricidade ao longo do ano.

Com base na perspectiva do próprio ReLuz com a substituição de 5 milhões de lâmpadas e a expansão de 1 milhão de novos pontos da rede de IP em todo o Brasil (ELETROBRÁS, 2006) ou mesmo na estimativa aproximada de um total de 13 milhões de pontos de IP espalhados no País (FRÓES-DA-SILVA, 2006), o potencial de economia de energia (ou consumo evitado) é significativo. Em uma primeira aproximação, através dos valores do MDC-IP teríamos o potencial de deixar de consumir mais de $2.000 \mathrm{GWh} / \mathrm{ano}$.

Como conclusão direta dos resultados deste trabalho, é recomendável que as ações de conservação de energia (como o ReLuz), devem ser planejadas de acordo com as características climáticas regionais. As variáveis meteorológicas, como insolação, podem ser inseridas no planejamento energético nacional nos diferentes níveis, seja através de políticas públicas ou na classificação das mesorregiões com maior potencial de conservação. Como demostrado no artigo, existem ganhos reais da inserção da variabilidade climática na avaliação dos programas de eficiência energética. 
Finalmente cabe observar que a produção de energia elétrica no Brasil está fortemente baseada em centrais hidrelétricas, cuja oferta apresenta forte variação sazonal em função das condições hídricas. Portanto os custos de energia elétrica são diferenciados ao longo do ano (período seco e úmido). Nesse sentido, o detalhamento do tempo de utilização na iluminação pública, sinalizando um maior consumo nos meses secos e com tarifas mais elevadas, reforça a conveniência de promover a introdução de lâmpadas eficientes, principalmente nas mesorregiões com as maiores diferenças entre o dia claro teórico e a insolação.

\section{Agradecimentos}

Ao Programa de Pós-Graduação em Engenharia de Energia da UNIFEI, onde este trabalho foi desenvolvido, a equipe da Eletrobrás e da Concessionária Light pela cessão das informações do RELUZ, ao CNPq (processo n. 142212/2011-3) e a CAPES (processo n. 14552/2013-2) pelo apoio financeiro. Os autores agradecem também os comentários e as sugestões dos revisores anônimos, que auxiliaram a melhorar a versão final do artigo.

\section{REFERÊNCIAS}

AHRENS, C. D. Meteorology today: an introduction to weather, climate and the environment. Fifth ed. St Paul: West Publishing, 1994. p. 592

ARIES, M. B. C.; NEWSHAM, G. R. Effect of daylight saving time on lighting energy use: A literature review. Energy Policy, v. 36, n. 6, p. 1858-1866, jun. 2008.

http://dx.doi.org/10.1016/i.enpol.2007.05.021

BAKER, E.; SOLAK, S. Climate change and optimal energy technology R\&D policy. European Journal of Operational Research, v. 213, n. 2, p. 442-454, set. 2011.

http://dx.doi.org/10.1016/..ejor.2011.03.046

BHANDARI, M.; SHRESTHA, S.; NEW, J. Evaluation of weather datasets for building energy simulation. Energy and Buildings, v. 49, p. 109-118, 2012.

http://dx.doi.org/10.1016/j.enbuild.2012.01.033

BLADH, M. Energy efficient lighting meets real home life. Energy Efficiency, v. 4, n. 2, p. 235-245, 3 set. 2011. http://dx.doi.org/10.1007/s12053-010-9092-4

BOUYER, J.; INARD, C.; MUSY, M. Microclimatic coupling as a solution to improve building energy simulation in an urban context. Energy and Buildings, v. 43, n. 7, p. 1549-1559, 2011.

http://dx.doi.org/10.1016/i.enbuild.2011.02.010

BRASIL. Agência Nacional de Energia Elétrica. Resolução Normativa no 414, de 9 de Setembro de 2010. Brasil: Aneel, 2010. http://www.aneel.gov.br/cedoc/ren2010414.pdf 
CARDOSO, R. B.; NOGUEIRA, L.A.H.; SOUZA, E.P.; HADDAD, J. An assessment of energy benefits of efficient household air-conditioners in Brazil. Energy Efficiency, v. 5, n. 3, p. 433-446, 23 set. 2011. http://dx.doi.org/10.1007/s12053-011-9137-3

CARDOSO, R.B.; NOGUEIRA, L.A.H.; HADDAD, J. Economic feasibility for acquisition of efficient refrigerators in Brazil. Appl Energ, v. 87, n. 1, p. 28-37, jan. 2010.

http://dx.doi.org/10.1016/j.apenergy.2009.05.025

CAVALCANTI, I. F. A.; FERREIRA, N. J.; DIAS, M.A.F.S.; JUSTI, M.G.A. Tempo e clima no brasil. 1. ed. São Paulo: Oficina de Textos, 2009. p. 464.

DE ROSA, A.; FERRARO, V.; KALIAKATSOS, D.; MARINELLI, V. Calculating indoor natural illuminance in overcast sky conditions. Applied Energy, v. 87, n. 3, p. 806-813, mar. 2010. http://dx.doi.org/10.1016/j.apenergy.2009.09.034

DUBOIS, M.-C.; BLOMSTERBERG, Å. Energy saving potential and strategies for electric lighting in future north european, low energy office buildings: A literature review. Energy and Buildings, v. 43, n. 10, p. 2572-2582, out. 2011. http://dx.doi.org/10.1016/j.enbuild.2011.07.001

ELETROBRAS. Centrais Elétricas Brasileiras. Avaliação dos resultados do PROCEL 2005. Rio de Janeiro, 2006.

FERRARO, V.; IGAWA, N.; MARINELLI, V. INLUX-DBR - A calculation code to calculate indoor natural illuminance inside buildings under various sky conditions. Energy, v. 35, n. 9, p. 3722-3730, set. 2010. http://dx.doi.org/10.1016/j.energy.2010.05.021

FRÓES-DA-SILVA, L. L. Iluminação pública no Brasil: aspectos energéticos e institucionais. 2006. (Dissertação de Mestrado). Universidade Federal do Rio de Janeiro, 2006. www.ppe.ufrj.br/ppe/production/tesis/llfroes.pdf

GELLER, H. SCHAEFFER, R.; SZKLO, A.; TOLMASQUIM, M. Policies for advancing energy efficiency and renewable energy use in Brazil. Energy Policy, v. 32, n. 12, p. 1437-1450, ago. 2004 http://dx.doi.org/10.1016/S0301-4215(03)00122-8

GHISI, E.; GOSCH, S.; LAMBERTS, R. Electricity end-uses in the residential sector of Brazil. Energy Policy, v. 35, n. 8, p. 4107-4120, ago. 2007. http://dx.doi.org/10.1016/j.enpol.2007.02.020

HEO, Y.; ZAVALA, V. M. Gaussian process modeling for measurement and verification of building energy savings. Energy and Buildings, v. 53, p. 7-18, out. 2012.

http://dx.doi.org/10.1016/j.enbuild.2012.06.024

IHM, P.; NEMRI, A.; KRARTI, M. Estimation of lighting energy savings from daylighting. Building and Environment, v. 44, n. 3, p. 509-514, mar. 2009.

http://dx.doi.org/10.1016/j.buildenv.2008.04.016

INMET. Manual de observações meteorológicas. Brasília: INMET, 1999.

INMET. Normais climatológicas do Brasil 1961-1990. Brasília: INMET, 2009.

INPE. Revista climanálise: edição especial comemorativa de 10 anos. Revista Climanálise, 1996. http://climanalise.cptec.inpe.br/ rclimanl/revista/

KOOMEY, J.; AKBARI, H.; BLUMSTEIN, C.; BROWN, M.; BROWN, R.; CALWELL, C.; CARTER, S.; CAVANAGH, R.; CHANG, A.; CLARIDGE, D.; CRAIG, P.; DIAMOND, R.; ETO, J. H.; FULKERSON,

Revista Produção Online, Florianópolis, SC, v.15, n. 4, p. 1399-1425, out./dez. 2015. 
W.; GADGIL, A.; GELLER, H.; GOLDEMBERG, J.; GOLDMAN, C.; GOLDSTEIN, D. B.; GREENBERG, S.; HAFEMEISTER, D.; HARRIS, J.; HARVEY, H.; HEITZ, E.; HIRST, E.; HUMMEL, H.; KAMMEN, D.; KELLY, H.; LAITNER, S.; LEVINE, M.; LOVINS, A.; MASTERS, G.; MCMAHON, J. E.; MEIER, A.; MESSENGER, M.; MILLHONE, J.; MILLS, E.; NADEL, S.; NORDMAN, B.; PRICE, L.; ROMM, J.; ROSS, M.; RUFO, M.; SATHAYE, J.; SCHIPPER, L.; SCHNEIDER, S. H.; SWEENEY, J. L.; VERDICT, M.; VORSATZ, D.; WANG, D.; WEINBERG, C.; WILK, R.; WILSON, J.; WORRELL, E.. Defining a standard metric for electricity savings. Environmental Research Letters, v. 5, n. 1, p. 014017, 9 jan. 2010. http://dx.doi.org/10.1088/1748-9326/5/1/014017

KOSTIC, M.; DJOKIC, L. Recommendations for energy efficient and visually acceptable street lighting. Energy, v. 34, n. 10, p. 1565-1572, out. 2009.

http://dx.doi.org/10.1016/j.energy.2009.06.056

KWAK, Y.; SEO, D.; JANG, C.; HUH, J.H. Feasibility study on a novel methodology for short-term real-time energy demand prediction using weather forecasting data. Energy and Buildings, v. 57, p. 250-260, 2013. http://dx.doi.org/10.1016/i.enbuild.2012.10.041

LI, D. H. W.; CHEUNG, K.L.; TANG, H.L.; CHENG, C.C.K. Identifying CIE standard skies using vertical sky component. Journal of Atmospheric and Solar-Terrestrial Physics, v. 73, n. 13, p. 1861-1867, ago. 2011. http://dx.doi.org/10.1016/j.jastp.2011.04.015

LI, D. H. W.; YANG, L.; LAM, J. C. Impact of climate change on energy use in the built environment in different climate zones - A review. Energy, v. 42, n. 1, p. 103-112, jun. 2012.

http://dx.doi.org/10.1016/j.energy.2012.03.044

LOPES, S. B. Eficiência energética em sistemas de iluminação pública. 2002. Dissertação (Mestrado). Universidade de São Paulo, 2002.

http://www.iee.usp.br/biblioteca/producao/2002/Teses/Dissertacao Sergio.pdf

MARTÍNEZ-CHICO, M.; BATLLES, F. J.; BOSCH, J. L. Cloud classification in a mediterranean location using radiation data and sky images. Energy, v. 36, n. 7, p. 4055-4062, jul. 2011.

http://dx.doi.org/10.1016/j.energy.2011.04.043

NOGUEIRA, L. A. H.; CARDOSO, R.B.; CAVALCANTI, C.Z.B.; LEONELLI, P.A. Evaluation of the energy impacts of the energy efficiency law in Brazil. Energy for Sustainable Development, v. 24, p. 58-69, 2015. http://dx.doi.org/10.1016/j.esd.2014.12.002

OLIVEIRA, A. DE; SILVEIRA, G. B. DA; BRAGA, J. DE M. Diversidade sazonal do consumo de energia elétrica no Brasil. Pesquisa e Planejamento Econômico., v. 30, n. 2, p. 211-257, 2000.

PASA, C.C.M.U.; PASA, L.A.; BRAGHINI-JUNIOR, A.; SOUZA, S.N.M. Avaliação da eficiência energética em edificações e sua relação com os materiais construtivos empregados. Produção Online, v. 12, n. 1, p. 229-247, 2012. http://dx.doi.org/10.14488/1676-1901.v12i1.873

QUADROS, R. Apuração do consumo de energia elétrica da iluminação pública. 2006a, p. 17. http://www.eletrobras.com/elb/procel/services/DocumentManagement/FileDownload.EZTSvc.asp?Do cumentID $=\{3 F 1 B 1 F 68-E B B C-454 D-810 C-86 C 8122 B 0786\} \&$ ServicelnstUID $=\{A E B E 43 D A-69 A D-$ 4278-B9FC-41031DD07B52\}

QUADROS, R. Apuração do consumo de energia elétrica da iluminação pública: estimativa ou medição. IBMEC, Rio de Janeiro, 2006b. 
SOLA, A. V. H.; XAVIER, A.A.P.; KOVALESKI, J.L.; RESENDE, L.M. Análise dos Fatores Determinantes para Eficiência Energética. Produção Online, v. 6, n. 1, p. 1-25, 2006. http://dx.doi.org/10.14488/1676-1901.v6i1.86

TERAMOTO, É. T.; ESCOBEDO, J. F. Análise da frequência anual das condições de céu em Botucatu , São Paulo. Revista Brasileira de Engenharia Agrícola e Ambiental, v. 16, n. 9, p. 985992, 2012. http://dx.doi.org/10.1590/S1415-43662012000900009

TIBA, C. Atlas solarimétrico do Brasil. Recife: UFPE. , 2003

VAREJÃO-SILVA, M. A. Meteorologia e climatologia. 2. ed. Recife: INMET, 2005. p. 522. http://www.agritempo.gov.br/modules.php?name=Downloads\&d op=getit\&lid=51

VIANELLO, R. L.; ALVES, A. R. Meteorologia básica e aplicações. 1. ed. Viçosa: UFV, 1991. p. 449

WMO. Guide to meteorological instruments and methods of observation WMO-N.8. 7. ed. Geneva: WMO, 2008. p. 681.

https://www.wmo.int/pages/prog/gcos/documents/gruanmanuals/CIMO/CIMO Guide-7th Edition2008.pdf

WOJNICKI, I.; ERNST, S.; KOTULSKI, L.; SEDZIWY, A. Advanced street lighting control. Expert Systems with Applications, v. 41, n. 4, p. 999-1005, mar. 2014.

http://dx.doi.org/10.1016/..eswa.2013.07.044

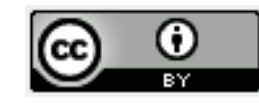

Artigo recebido em 23/01/2015 e aceito para publicação em 17/11/2015

DOI: http://dx.doi.org/ 10.14488/1676-1901.v15i4.1974 


\section{APÊNDICE}

Cálculo das correlações entre a diferença do dia claro teórico (Td) e insolação (I) de algumas mesorregiões analisadas e discutidas no Quadro 5.
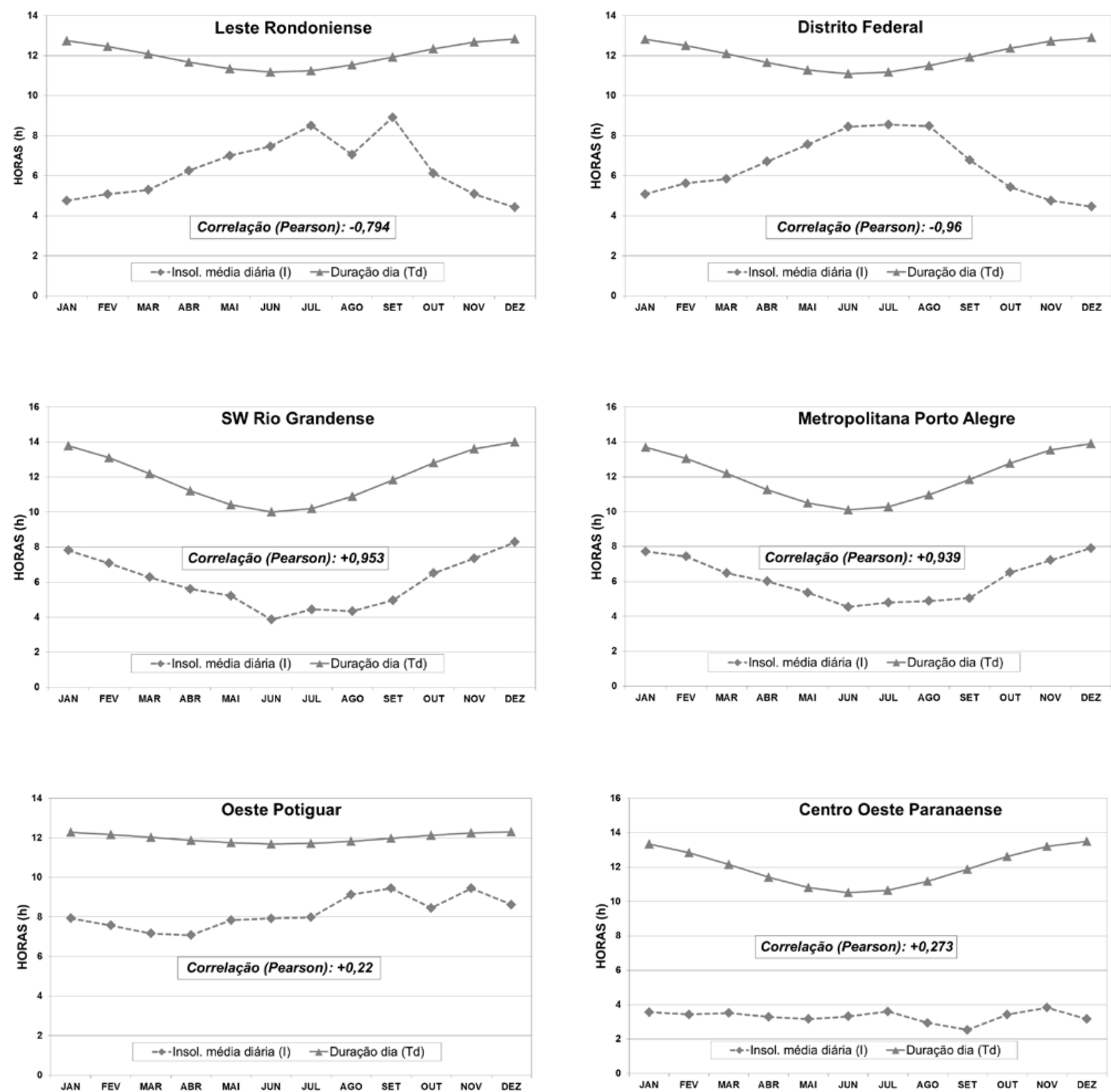

Revista Produção Online, Florianópolis, SC, v.15, n. 4, p. 1399-1425, out./dez. 2015. 